\section{VIOLENCIA URBANA, EXCLUSIÓN SOCIAL Y PROCESOS DE GUETIZACIÓN: LA TRAYECTORIA DE LA POBLACIÓN SANTA ADRIANA}

Graciela Alejandra Lunecke Reyes ${ }^{1}$

\section{Resumen}

El presente artículo evidencia que el tráfico de drogas en la población Santa Adriana está asociado a los procesos de exclusión social que han debido enfrentar los vecinos desde la etapa fundacional del barrio. Si bien este tipo de delincuencia es la que causa un mayor nivel de deterioro en la calidad de vida de sus habitantes, el análisis realizado releva que no es una actividad aislada. En el vecindario se observan otras actividades ilegales y figuras delictivas cuyo origen se remonta al origen del vecindario. En este sentido, la trayectoria barrial nos habla de la presencia de mapas normativos diferenciados a la sociedad que tienen larga

\section{URBAN VIOLENCE, SOCIAL EXCLUSIÓN AND GHETTOIZATION: THE HISTORY OF SANTA ADRIANA}

Graciela Alejandra Lunecke Reyes ${ }^{1}$

\section{Abstract}

This paper shows the relationship between drug trafficking and the social exclusion processes faced by residents of Santa Adriana during the early days of this community. Although this type of crime has the greater impact on people's lives, this analysis reveals that drug trafficking is not an uncommon activity. There are other types of illegal practices dating back to the origins of this neighborhood. In this sense, Santa Adriana shows different and old 
data. Al buscar explicaciones posibles, el análisis en materia económica nos muestra una historia de exclusión caracterizada por condiciones de precariedad laboral, económica y social de las familias. También, en la trayectoria social del barrio se identifican factores asociados. Los vínculos comunitarios y sociales que en un pasado ayudaron a las familias a superar las desventajas materiales, se fueron debilitando con el tiempo. Estos procesos que confluyen en el territorio facilitaron el desarrollo de actividades delictuales, dentro de las cuales el tráfico de droga es su expresión más latente.

PALABRAS CLAVE: VIOLENCIA URBANA, BARRIOS, PROCESOS DE GUETIZACIÓN, EXCLUSIÓN SOCIAL.

Fecha de recepción: 26.10.11

Fecha de aceptación: 23.03.12

1 Chile. Licenciada en Historia y Ciencias Políticas. Magíster en Desarrollo Urbano, Pontificia Universidad Católica de Chile.

288 revista invi № 74 / Mayo 2012 / Volumen № 27: 287-313 normative patterns. In an attempt to find the reasons of this problem, the economic analysis reveals a history of exclusion characterized by poor work, economic and social conditions. In addition, this research identifies associated factors. The commity and social ties that once helped families to overcome material disadvantage have weakened over time. These processes contributed to the rise of crime, especially drug trafficking.

KEYWORDS: URBAN VIOLENCE, NEIGHBORHODS, GHETTOIZATION PROCESSES, SOCIAL EXCLUSION
Received: 26.10.11

Accepted: 23.03.12

1 Chile. BA in History and Social Science. MBA in Urban Development, Pontificia Universidad Católica de Chile. 


\section{Introducción}

En las últimas décadas, las ciudades en América Latina han sufrido profundas transformaciones económicas y sociales que han acentuado los procesos de segregación espacial y la formación de sectores marginales empobrecidos y excluidos. Ellos concentran una serie de desventajas sociales y económicas y que enfrentan un significativo nivel de violencia urbana. Chile no es una excepción a ello. Desde 2000 el tráfico de drogas se ha convertido en un tema de preocupación pública. Barrios como La Legua, La Victoria y Santa Adriana entre otros, han sido intervenidos por el Estado dadas las condiciones de inseguridad en que viven sus vecinos. Este tipo de delincuencia ha hecho reaparecer en la agenda pública la necesidad de abordar con urgencia las precarias condiciones de vida que enfrentan los vecinos.

A través de este artículo se busca contribuir al análisis de la criminalidad urbana desde una aproximación a los procesos de exclusión social y su relación con los procesos de guetización. También se quiere aportar al análisis multidimensional de la violencia y de la criminalidad urbana ${ }^{2}$. Con estos objetivos, las siguientes páginas buscan responder

2 Este artículo se basa en una investigación realizada en 2008 en el marco del desarrollo de la tesis para optar al grado de Magíster en Desarrollo Urbano de la Pontificia Universidad Católica de Chile. Las fuentes de información primaria utilizadas corresponden a entrevistas realizadas en el marco de dicha investigación. a ¿cómo y por qué se desarrollan estas redes un vecindario determinado?, y icómo influyen los aspectos de carácter social, político, cultural y económico en ello?

El artículo se divide en cuatro acápites. En primer lugar, se presenta el problema de las bandas de tráfico de drogas en el barrio Santa Adriana y cómo ello afecta la vida de los vecinos ${ }^{3}$. En un segundo acápite, se sintetizan los principales elementos conceptuales que orientan el análisis del caso de estudio. En tercer lugar, se analiza la trayectoria barrial en materia social, cultural y económica. Por último, a modo de conclusiones, se sintetizan los principales hallazgos del estudio, dando cuenta de la relación que existe entre los procesos de exclusión social y la violencia urbana que se evidencia en Santa Adriana.

\section{Violencia urbana en barrios: Santa Adriana y el tráfico de drogas}

"Yo estoy en mis cuatro paredes y no me meto con la gente de allá afuera. Se estén matando entre disparos... yo no salgo y no participo en nada y creo que toda la gente limpia de acá, la gran mayoría es así como yo" (Mujer pobladora, 50 años).

3 La descripción de las bandas y de sus efectos en el barrio se basa en la información disponible para la última década y en el estudio realizado por la autora en 2008. 
Santa Adriana es un vecindario que se localiza en la zona sur de la ciudad de Santiago, cuenta con una población de 12.227 habitantes según el Censo Nacional de 2002, cifra que desciende a 11.409 según el estudio realizado por la Universidad Alberto Hurtado en 2007. Según esta misma fuente de información, Santa Adriana cuenta con una población de 11.409 habitantes y tiene un total de 2.656 viviendas. Como se observa en la gráfica siguiente, la cercanía a vías estructurantes, hace de Santa Adriana un barrio central en términos de conectividad a la ciudad.

Según información del Ministerio de Vivienda y Urbanismo se evidencia que Santa Adriana es una población con una estructura definida por lotes que data desde su época fundacional (1961-1965). En su mayor parte se trata de viviendas unifamiliares (2.491 del total) y sólo el 7\% está formado por bloques de departamentos. Como se aprecia a continuación, la población está configurada en cuatro sectores definidos:

El origen de Santa Adriana se remonta a los procesos de radicaciones que se desarrollaron bajo el gobierno de Alessandri. Se fundó en 1961 a partir de la toma de terreno en la ex chacra Santa Adriana y "fue realizada por 300 familias que venían de poblaciones como La Victoria, Lo Valledor, La
Legua, Matucana, Germán Riesco y Quinta Normal. Junto a estas primeras familias, luego se sumaron 1.500 que venían de una toma realizada en el sector de Estrella Polar y grupos familiares organizados a través de comités de allegados, que habían postulado a la vivienda propia a través de la Corporación de Vivienda de la época y que provenían de diferentes comunas de Santiago"'.

Desde sus inicios, esta población ha sido conocida en el escenario público nacional. Primero, porque con la toma de terreno sus pobladores pusieron de manifiesto públicamente la demanda social que existía en materia de viviendas en el país. Luego, y tras el golpe militar de 1973, Santa Adriana fue conocida por ser foco de la represión política dada la tradición de izquierda de sus dirigentes vecinales. A partir de 2000 vuelve al tapete público cuando los dirigentes demandan mejores condiciones de seguridad. Santa Adriana, junto a la población La Legua y La Victoria fue uno de los tres primeros barrios intervenidos policial y socialmente por el Estado chileno con el objeto de mitigar los efectos de la violencia vinculada al tráfico de drogas que afectaba a sus vecinos.

Así, desde la última década la población ha sido objeto de intervención de importantes políticas de

4 Garcés, Mario, 2002, p. 199. 
FIGURA 1: LOCALIZACIÓN POBLACIÓN SANTA ADRIANA

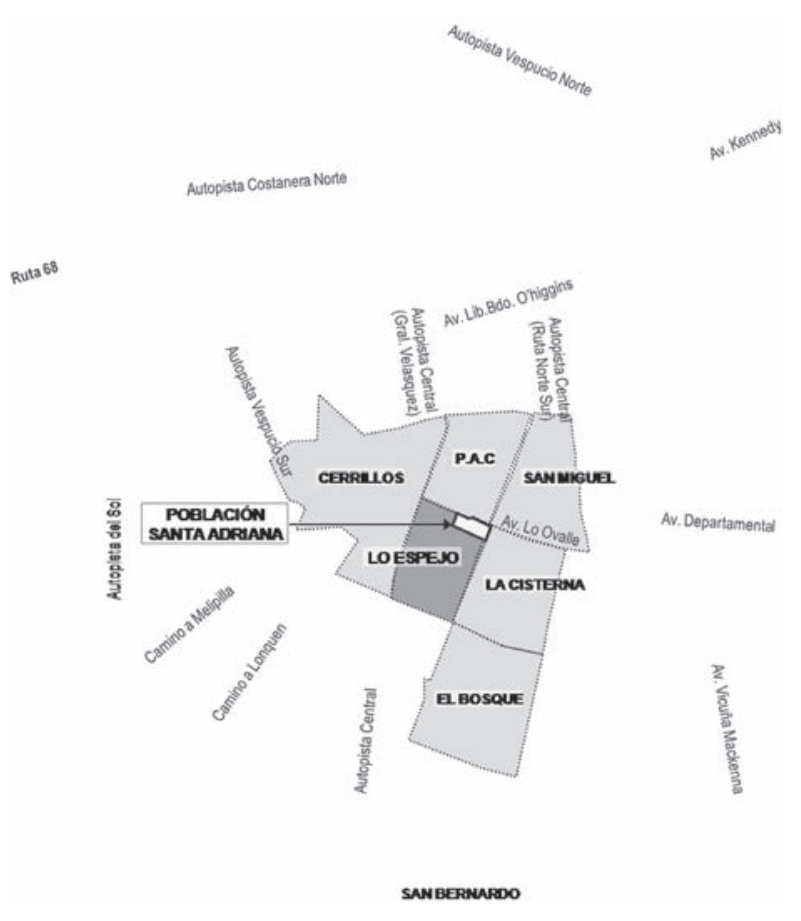

Fuente: Diagnóstico Integral Programa Quiero Mi Barrio - Población Santa Adriana; MINVU; 2007.

\section{FIGURA 2. SECTORES POBLACIÓN SANTA ADRIANA}
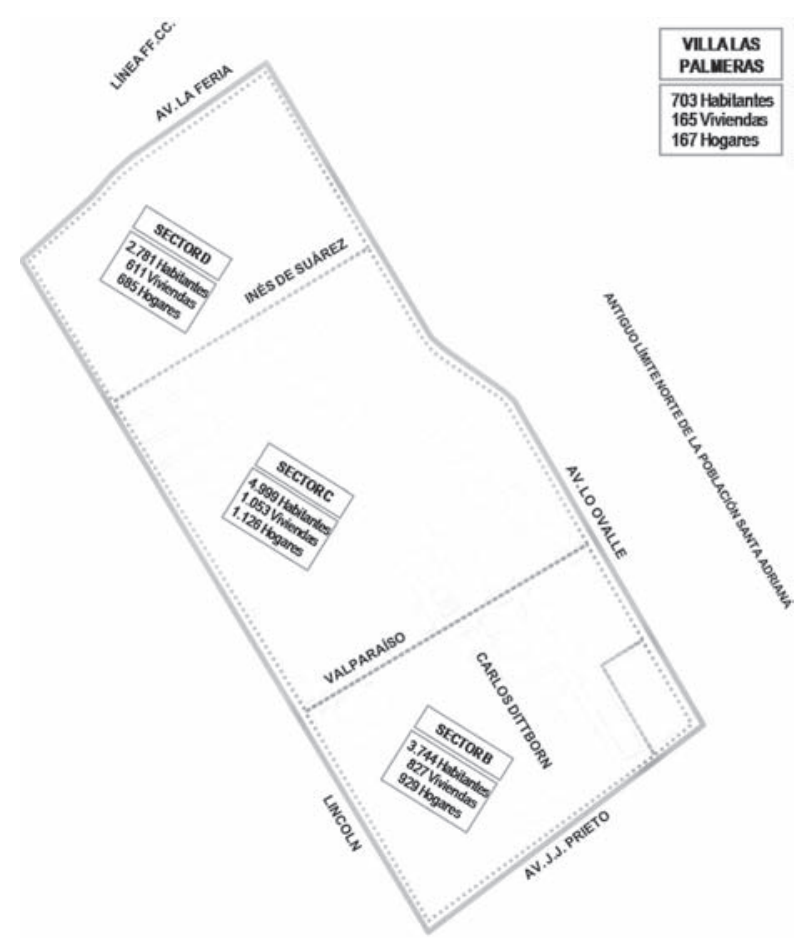

Fuente: Diagnóstico Integral Programa Quiero Mi Barrio - Población Santa Adriana; MINVU; 2007. 
Gobierno $^{5}$, instalándose en el debate público las difíciles condiciones de vida que enfrentan los vecinos de este barrio (y de otros vecindarios similares). Los diagnósticos realizados en el marco de estas intervenciones públicas ${ }^{6}$ evidencian que junto a las desventajosas condiciones socioeconómicas de las familias, existen altos niveles de inseguridad producto de la violencia ejercida por bandas dedicadas al tráfico de drogas.

\section{LOS PROTAGONISTAS DE LA VIOLENCIA: LAS BANDAS}

Según la investigación realizada por la Universidad Alberto Hurtado en 2004, "estas bandas nacen a fines de la década de los ochenta y la ocupación que estas hacen de los espacios públicos mediante el uso de la violencia, ha sido el principal foco de temor de los vecinos" ${ }^{7}$. La violencia armada, usada en disputas entre ellas y/o en el amedrentamiento que hacen a los vecinos, es lo que mayor alarma genera. Según la información policial disponible

5 Entre 2002 y 2005, el Ministerio de Interior -a través del Programa Barrio Seguro-focalizó una serie de estrategias de carácter policial y social. A partir de 2006, el Ministerio de Vivienda y Urbanismo -con el Programa Quiero mi Barrio- ha realizado una intervención orientada a recuperar urbanamente el vecindario. Esta intervención aún se encuentra vigente.

6 Los estudios realizados en el marco de estas intervenciones públicas refieren al período 2002 -2008 y fueron realizados por la Pontificia Universidad Católica, la Universidad Alberto Hurtado, HABITERRA, PRODEMU, y MINVU. Sus referencias se detallan en la bibliografía final.

7 Universidad Alberto Hurtado, 2004a, p. 28. para la década, en el año 2007 existían al menos cinco bandas con alta capacidad de organización ${ }^{8}$. Al respecto, Lunecke y Ruiz destacan que "estos grupos se caracterizan por tener estructuras jerárquicas y una clara distribución de roles y funciones. Se organizan y trabajan en base a solidaridades y lazos de confianza, que son sustento para la protección de la actividad ilegal"9.

El origen del negocio de la droga en la población se asocia a las familias que estaban involucradas en otras actividades delictivas (robo) en décadas pasadas y que ingresaron la droga al barrio a través de los contactos internacionales que manejaban. Así lo reporta el estudio etnográfico realizado por la Universidad Alberto Hurtado en 2004: "Si bien no es considerado un peligro, la figura del lanza internacional (ladrón que roba en el extranjero) se vincula con la del narco (narcotraficante). Claro ejemplo es el cartel de los Rivas (familia de la población), a quienes antes de ser narcos se les adjudica un pasado de lanzas internacionales"10.

8 Lunecke, Alejandra. 2008, p. 27

9 Lunecke, Alejandra y Ruiz, Juan Carlos. 2005, p. 243.

10 Universidad Alberto Hurtado, 2004b, p. 14 


\section{LA RELACIÓN DE LAS BANDAS CON LOS VECINOS}

Si bien, la figura de las familias vinculadas al narcotráfico genera alto temor en la población, ellas y sus miembros no son percibidos como grupos aislados sino que existen lazos de sociabilidad que relativizan los juicios sobre su presencia. Según lo señala el estudio etnográfico de 2004, "la sola presencia del narco no constituye directamente un motivo de conflicto. En su doble condición de vecino y delincuente, su presencia es enjuiciada únicamente frente al incremento del estigma social, la amenaza o frente a la figura de la balacera, no así frente a su presencia y al desarrollo del comercio ilícito. El deambular de los narcos por los pasajes de la población es cotidiano y la sensación de temor de los vecinos, la mayor parte del tiempo, se entremezclan con los saludos y breves conversaciones"11. Esto se corrobora en el relato de una vecina entrevistada en 2008:

"yo soy indiferente, a mí no me interesa si el de al lado es traficante, el otro es internacional... cada cual hace su vida, con tal de que no me estén molestando a mí, yo estoy bien... ¿Temor? A ellos, no, ni tanto, porque como nunca he tenido problemas con ellos, cachái, nunca ellos han venido a mi puerta a amenazarme, a darme un problema, entonces no te puedo decir que temor o que me afecten psicológicamente, no. Como ellos están en su lado y yo estoy en el mío, no me hacen nada..." (Mujer Vecina, 52 años).

11 Universidad Alberto Hurtado, 2004b, p. 35.

\section{FIGURA 3. MEMORIAL DEL "BRYAN" EN SANTA ADRIANA. NIÑO MUERTO POR BALACERAS ENTRE BANDAS.}



Fuente: Elaboración propia.

\section{LOS EFECTOS EN EL VECINDARIO}

A nivel individual, uno de los efectos más directos de esta violencia "es el alto grado de inseguridad que experimentan los vecinos"12. El temor influye más que el mismo delito en la vida diaria y ha hecho que durante más de una década los vecinos de esta población modifiquen la forma en que usan los espacios públicos. Al respecto, el Censo realizado por la Universidad Alberto Hurtado en 2007

12 ECOSOC, 2003, p. 4. 
da cuenta que "el 71\% de la población se siente "siempre" o "frecuentemente" expuesta a balaceras, el $46 \%$ a riñas o peleas y el $56 \%$ de la población manifiesta que "nunca" o "casi nunca" se siente segura estando en la calle." ${ }^{13}$ Restringir los horarios de salida, evitar ciertas calles y pasajes, recluirse en los hogares, son algunas formas mediante las cuales los vecinos gestionan sus rutinas frente al riesgo que impone la violencia armada.

Otro efecto se relaciona con el grado de satisfacción que los habitantes tienen con sus barrios. Para Santa Adriana se constata "un alto nivel de insatisfacción de los vecinos con el barrio. Evaluando desde 1 y 7 , se observa que un 38,2\% de los encuestados evalúa negativamente su barrio, con nota "insuficiente", mientras un 31,8\% lo evalúa como "regular". Sólo un 23,3\% de los encuestados refirió al barrio como "bueno"14.

Relacionado a lo anterior, la violencia produce en vecinos el deseo de emigración poblacional ${ }^{15}$. Para el caso de Santa Adriana, "casi la mitad de las y los jefes de hogar de Santa Adriana (48,6\%) quiere cambiarse de barrio, y la gran mayoría quiere irse fuera de la comuna"16.

El daño que causa la violencia se expresa también en el tejido social. "En barrios que enfrentan el

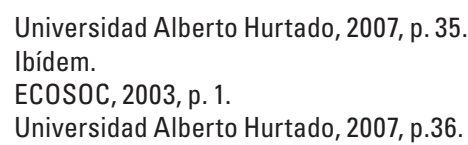

accionar de bandas de tráfico de drogas, se generan una serie de desconfianzas interpersonales lo que muchas veces se traduce en bajos niveles de participación en organizaciones vecinales, o bien, en no querer vincularse con el vecino"17. En este caso, "más de la mitad de los encuestados declara que sólo confía en 'algunos pocos' vecinos dentro de su barrio; mientras que sólo un 21,4\% confía en la mayoría. Asimismo, un 51,25\% de los entrevistados declara conocer a sus vecinos pero relacionarse poco con ellos, mientras que el 23,7\% declara "no meterse con nadie"18.

\section{EL ESTIGMA TERRITORIAL}

Otra importante implicancia de este fenómeno, es el alto grado de estigmatización social que enfrentan los barrios que son conocidos públicamente por estos problemas. El estigma genera una sensación de frustración en el imaginario social de quienes los habitan. Para el caso de Santa Adriana el siguiente relato es elocuente al respecto:

"Yo he sido afectado en muchas ocasiones, he tenido que dar direcciones de mis hermanos de La Florida para conseguir una tarjeta de crédito en Falabella ${ }^{19}$, porque en dos o tres ocasiones por dar la dirección de aquí no me la dieron. Además para el tema de comprar en las

17 Lunecke, Alejandra y Eissmann, Ignacio, p. 79

18 Universidad Alberto Hurtado, 2007, p. 37.

19 Fallabella es una reconocida casa comercial en Chile del rubro del "retail". 
grandes tiendas, no me han querido venir a dejar las cosas porque me dicen que no. Eso nos ha marcado mucho." (Hombre, Vecino, 49 años).

De esta forma, esta violencia lo que produce es "una sensación permanente en los vecinos de estar impedidos de ocupar los espacios de su vida cotidiana, lo que genera a su vez un sentimiento de pérdida del entorno y también de desconfianza en la socialización con los otros"20.

\section{Las causas: una aproximación desde la exclusión social y los procesos de guetización}

La delincuencia y la violencia urbana cuentan con una amplia gama de teorías desarrolladas por la criminología que refieren a los factores que la explican. Sin embargo, aún "los criminólogos no han podido establecer el cómo se relacionan la exclusión social, la desigualdad y el delito"21. Como se ha señalado antes, este artículo quiere hacer una contribución en esta línea, indagando sobre la posible asociación entre factores vinculados a la exclusión social de los territorios y el desarrollo de actividades delictivas.

Para ello, se entenderá la exclusión social como "la acumulación de procesos confluyentes con

20 ECOSOC, 2003, p. 3.

21 Weather, Don y Lind, Bronwyn. 2001, p. 17. rupturas sucesivas que, arrancando del corazón de la economía, la política y la sociedad, van alejando e inferiorizando a personas, grupos, comunidades y territorios con respecto a los centros de poder, los recursos y los valores dominantes" 22 . Esta noción también implica asumir que la exclusión social se genera a través de procesos que se dan en el tiempo y que producen un deterioro de las condiciones de vida de personas o grupos determinados. Estos procesos aluden a diferentes aspectos de la vida de los sujetos (sociales, políticos, económicos, culturales, ambientales). Para efectos de este artículo nos centraremos en la dimensión económica, social y cultural que involucran los procesos de exclusión.

La dimensión económica de la exclusión refiere a la relación existente entre los sujetos y el sistema económico en general. Uno de los vínculos más significativos en este ámbito es el que se establece a través del mercado de trabajo. Ello porque, "el vínculo laboral constituye tanto una fuente de ingreso para los sujetos y de sus familias como también un espacio de pertenencia social y una fuente de status"23. El debilitamiento de este vínculo y /o su ruptura se puede dar porque los sujetos se encuentran desempleados y/o, por que enfrentan malas condiciones de empleo (informalidad, bajas remuneraciones, desprotección social, etc.). Estas condiciones están determinadas en gran parte por el nivel educacional.

22 Estivill, Jordi, 2003, p. 19.

23 Sunkel, Guillermo, 2003, p. 305. 
Otra fuente de integración (o exclusión) al sistema económico lo presenta la capacidad económica de los sujetos y sus familias, la que es determinada por la tenencia de activos económicos (ingresos, capacidad de endeudamiento, capacidad de ahorro y/o la propiedad de bienes). La inexistencia de este tipo de recursos junto al desempleo y la precariedad laboral llevan a que los grupos más pobres se alejen de los centros de recursos y oportunidades que permiten una trayectoria de movilidad social. Al respecto, Katzman señala: "dicho aislamiento se convierte en un obstáculo importante para acumular los activos que se necesitan para dejar de ser pobres" 24 .

Estas condiciones de exclusión económica pueden ser reducidas o incluso revertidas por la acción del Estado. Al respecto, Wacquant al analizar las condiciones de exclusión entre el gueto norteamericano y los barrios marginales de París, señala que el grado de penetración del Estado en un territorio determinado explica el nivel de aislamiento y deterioro de las condiciones de vida de un vecindario desaventajado socialmente:“...la exclusión se sostiene en la pertenencia etnorracial reforzada por la clase social y por el Estado dentro del cinturón negro, mientras que opera prioritariamente sobre la base social y resulta parcialmente atenuada por el Estado en el cinturón rojo (...)"25.

24 Katzman, Rubén, 2002 p. 173.

25 Wacquant, Loic. 2007, p. 200.
Por otra parte, la dimensión social de la exclusión alude a los lazos existentes entre los sujetos y la sociedad. En condiciones de exclusión hay un aislamiento entre los sujetos y otros grupos sociales producto de la ineficacia que presentan las instituciones de socialización para integrarlos. La literatura especializada considera a la familia, a la escuela y sistema educativo y al barrio como los principales sistemas sociales que deben integrar a los sujetos al resto de la sociedad ${ }^{26}$. En condiciones de marginalidad ni las familias ni las escuelas tienen capacidad de integrar a los sujetos, agudizándose la marginación y el aislamiento. Por ello, el tipo de socialización que las familias ofrecen, los tipos de vínculos que existen en el vecindario; el tipo de socialización y los recursos que ofrecen las escuelas permiten establecer cuál es el grado o nivel de integración de los sujetos a la sociedad o cuán alejados se encuentran de ella. En territorios desaventajados, y cuando las familias y las escuelas no cumplen con su función de integración social, los vínculos comunitarios se constituyen en una barrera frente al delito, en un mecanismo de control social informal y de contención de los conflictos.

Por último, la dimensión cultural de la exclusión, apunta a la integración de individuos y de grupos a los mapas normativos y valores socialmente

26 Vandershueren, Franz y Lunecke, Alejandra, 2004, p. 45. 
vigentes $^{27}$. En determinados sectores poblacionales, las dinámicas sociales y sus significados adquieren variaciones respecto de aquellas conductas y prácticas establecidas socialmente. La marginación de ciertos espacios de intercambio y socialización, y la inclusión en otros con características opuestas, configura un núcleo alternativo de valores, de patrones de conducta, códigos sociales e incluso una ética que puede contravenir las concepciones del resto de la sociedad. Como señala Bauman, "en territorios marginalizados la comunidad acepta y desarrolla una forma de organización diferente, que actúa como mecanismo de salida a los problemas que se deben enfrentan. El desarrollo de economías ilegales es incluso justificado por el resto de la comunidad y el vecindario. Así, por lo general, las relaciones que se establecen con los sujetos y familias involucradas en ellas, son de amistad o de indiferencia, pero no existen sanciones valóricas o normativas sobre ellos". ${ }^{28}$

Especialistas del crimen han puesto el interés en estos procesos de construcción cultural. Sutherland destaca que "un individuo llega a convertirse en delincuente porque acepta que la ley puede ser violada. En ello interviene el contexto en el cual se mueve, los grupos personales más cercanos (familiares, amigos, pares) con los que vive y en los

$\begin{array}{ll}27 & \text { Ibídem. } \\ 28 & \text { Bauman, Zygmunt. 2004, p. } 114 .\end{array}$ que las definiciones desfavorables a la ley exceden a las favorables. Así se aprenden en forma activa las actitudes, las pautas, los motivos y las justificaciones de actos criminales" 29 . Por ello, es posible sostener que existe una relación positiva entre los procesos de aprendizaje del delito y la ruptura de las normas, y las características sociales de la familia, la escuela y el barrio. Así, "en barrios donde los sujetos están expuestos de manera cotidiana a situaciones de violencia y delincuencia, es muy probable que, especialmente los más jóvenes, desarrollen comportamientos antisociales y se involucren en actos ilegales"30.

Si bien el análisis de los procesos de exclusión generalmente refiere a los vínculos entre los sujetos y la sociedad, estos procesos no sólo se dan en el nivel individual sino que también refieren a territorios. Estos se caracterizan principalmente por vivir en desventaja frente al resto de la sociedad, enfrentar altos niveles de estigmatización social y se encuentran por lo general, segregados. Para Marcuse estos barrios son producto de la localización forzada, es decir refiere a aquellos grupos sociales que no tienen capacidad de elegir su residencia ${ }^{31}$. Estos grupos son "los más pobres que terminan siendo excluidos de determinados espacios urbanos y que son forzados a aglomerarse en las

29 Sutherland, Edwin y Cressey, D. 1970, p. 79.

30 Lunecke, Alejandra y Vanderschueren, Franz. 2004, p. 46.

31 Marcuse, Peter, 1997, p. 51. 
peores áreas de la ciudad"32. En diversas ciudades latinoamericanas y en específico en Santiago, estos territorios se localizan en la periferia urbana y se caracterizan por tener una población laboralmente activa con bajas probabilidades de ingresar de forma permanente a puestos de trabajos estables y con bajas probabilidades de acceder a mejores condiciones socioeconómicas.

Al respecto Katzman observa que en las ciudades latinoamericanas existe una "concentración espacial históricamente inédita de personas con aspiraciones propias de la vida urbana, pero con graves privaciones materiales y escasas esperanzas de alcanzar logros significativos (...) lo que suscita fuertes sentimientos de privación relativa. Bajo estas circunstancias, se favorece la germinación de los elementos más disruptivos de la pobreza"33.

Es así como la violencia urbana puede ser abordada desde una perspectiva que pone el acento en los procesos que llevan a la ruptura de los vínculos existentes entre territorios determinados y la sociedad. Ello porque la violencia y la criminalidad constituyen formas de malignidad social que se observan en barrios excluidos y desaventajados. En estos vecindarios el surgimiento de mafias delincuenciales es un fenómeno frecuente

32 Peach, Ceri, 2005, p. 54

33 Katzman, Rubén, 2001, p. 181.

298 revista invi № 74 / Mayo 2012 / Volumen № 27: 287-313 y han hecho que estos barrios se conviertan, como dice Wacquant, en "lugares etiquetados como no-go-areas, barrios 'que dan miedo', o 'zonas sin ley' donde sólo tolerarían vivir los desechos de la sociedad"34.

Estos procesos de acumulación de desventajas en los territorios permiten observar la existencia de barrios con características de gueto. Aun cuando no existe consenso académico respecto a la especificidad del concepto y a los elementos particulares que determinan su condición, en diversos análisis se utiliza este concepto para referir a un territorio que evidencia cierto grado de homogeneidad social en el espacio y que es producida por fuerzas no voluntarias ${ }^{35}$. Esta homogeneidad refiere a su composición social, ya sea esta de carácter étnico racial, cultural o socioeconómica. Así, “... en cuanto al tipo ideal, el gueto puede caracterizarse como una formación socio-espacial restringida, racial y/o culturalmente uniforme, fundada en la relegación forzada de una población negativamente tipificada"36. Para Bauman, "las principales lógicas que explican la configuración del gueto son de carácter económico y suceden especialmente en el mercado laboral a través del aumento del desempleo" ${ }^{37}$. Junto a ello se suma, a juicio del autor, el retroceso que tiene el Estado social para contener o revertir estos procesos a

34 Wacquant, Loic. 2007,46

35 Marcuse, Peter.2001, p. 3.

36 Wacquant, Loic. 2007, p. 43.

37 Bauman, Zigmunt. 2004, p. 126 
FIGURA 4. DIAGRAMA ENFOQUE TEÓRICO: PROCESOS DE EXCLUSIÓN SOCIAL, ECONÓMICA Y CULTURAL DEL BARRIO
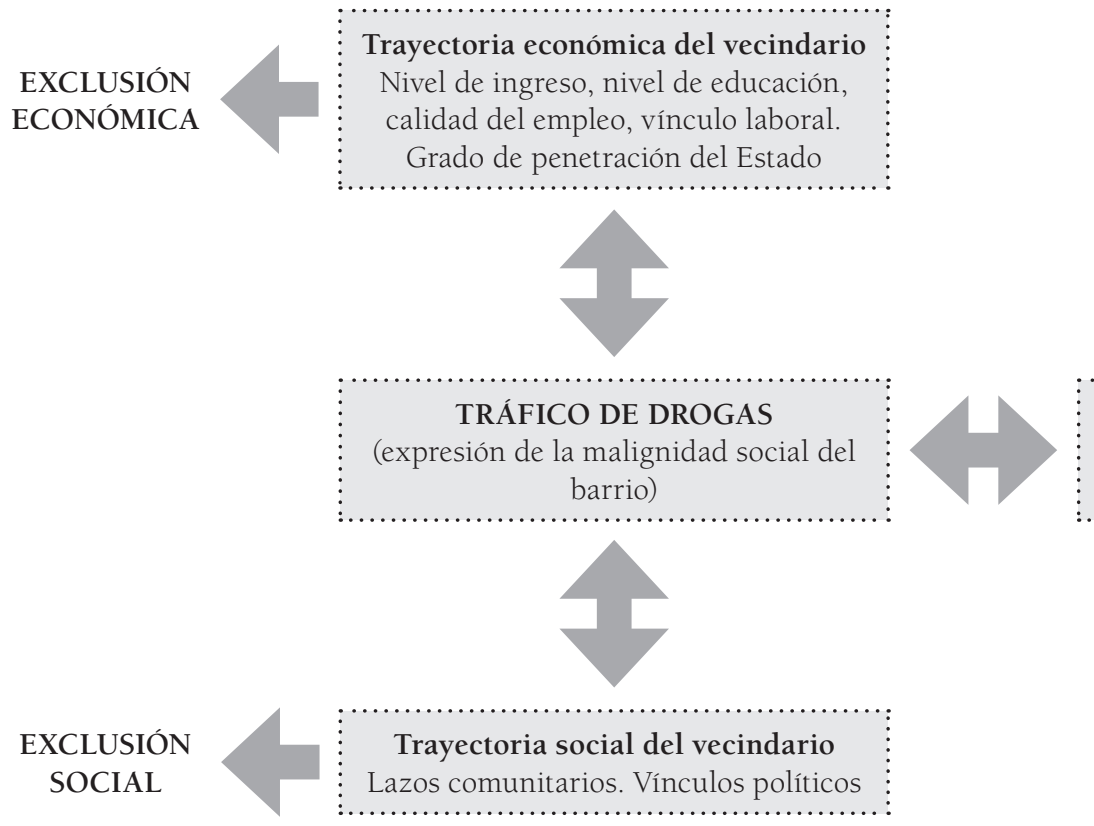

Trayectoria cultural del vecindario: Mapas normativos-valóricos imperantes

1961

Fuente: Elaboración propia en base a fuentes teóricas revisadas. 
través de políticas de mayor protección social. Con ello, el gueto "opera como uno de los principales instrumentos de exclusión en la sociedad actual"38.

De esta forma, el estudio de la violencia vinculada al tráfico de drogas en la población Santa Adriana se basa en matrices teórico-conceptuales asociadas a la exclusión social y a los procesos de guetización. Con el objeto de explicar el desarrollo y arraigo de este tipo de actividades ilegales en Santa Adriana, a continuación se presenta un diagrama que sintetiza los principales aspectos que serán analizados.

\section{Procesos de exclusión social y trayectoria barrial}

Como se ha señalado, uno de los aspectos que caracteriza el grado de exclusión de un territorio es el tipo de vínculo que existe entre sus residentes y la sociedad, ya sea con el sistema económico, en el ámbito social y ámbito normativo-cultural. Desde esta aproximación, el grado de aislamiento de sectores empobrecidos está influenciado por el nivel de segmentación laboral y educacional que tienen los sujetos y sus familias; por el grado de penetración que tienen las instituciones públicas para compensar las precariedades sociales y económicas; por la capacidad de los sujetos y las familias de integrarse a otros grupos sociales y por el nivel

38 Wacquant, Loic. 2007, p. 64.

300 revista invi № 74 / Mayo 2012 / Volumen Nº 27: 287-313 de integración al mapa de valores y normas vigentes en la sociedad. Estos factores contribuyen a explicar cómo a lo largo del tiempo se desarrollan procesos de exclusión que favorecen condiciones propicias para que los sujetos y las familias se involucren en actividades delincuenciales. El acceso material y económico que produce el mercado de la droga reporta recursos a las familias y les permite integrarse vía consumo a la sociedad; la pertenencia a la banda y a la cultura criminal reemplaza muchas veces las normas y valores vigentes en el resto de la sociedad; y el vínculo social que se establece en la red de tráfico responde a lógicas de reciprocidad y confianza, que muchas veces son débiles y/o inexistentes en el ámbito comunitario.

\section{LA TRAYECTORIA ECONÓMICA DEL VECINDARIO}

Desde la etapa fundacional, las familias de la población Santa Adriana han enfrentado precarias condiciones socioeconómicas. Esto se constata al comparar antecedentes históricos con información de la última década. El estudio de Garcés al respecto es elocuente: "Las primeras familias que llegaron a Santa Adriana y participaron en la Toma, se caracterizaron por ser pobres; no ganaban lo suficiente para arrendar o comprar sus casas; estaban cesantes o se trataba de mujeres solas, jefas de hogar, y todos eran de muy bajos recursos económicos"39. El relato de los vecinos consignado en la historia oral

39 Garcés, Mario. 2002, p. 211. 
realizada por Prodemu en 2004 también muestra que las familias que llegaron a la población a través de los comités de allegados eran mayoritariamente obreros sin calificación, empleados en fábricas y los cuales constituían la única fuente de ingresos del hogar porque en general las mujeres no trabajaban $^{40}$. Según el mismo estudio estas condiciones de precariedad se agudizaron con la crisis económica que vivió el país a principios de los ochenta y que produjo una fuerte cesantía en todas las zonas más pobres de las ciudades: "En Santa Adriana muchos miembros de los hogares se vieron forzados a dejar los estudios y se tuvieron que emplear en los programas temporales generados por el Estado para enfrentar la crisis"41. Para la última década, la información del Observatorio Social de la Universidad Alberto Hurtado señala que "la mayoría de los hogares cuentan con un ingreso mensual inferior a los $\$ 250.000$, siendo esta cifra menor en los hogares que presentan jefatura de hogar femenina, lo que es relevante dado que los hogares con jefatura femenina alcanzan un 35\% del total de hogares. ${ }^{42}$

Respecto a la situación de la fuerza de trabajo según el mismo informe de 2007, el 62,1\% de la población en edad activa se encuentra ocupada, existiendo un 21,8\% de desempleo en la población. Por otra parte, se vislumbran índices de inactividad

40 Prodemu, 2004, p. 12

41 Ibídem, p. 21.

42 Universidad Alberto Hurtado, 2007, p. 40.
TABLA 1. INGRESO PROMEDIO MENSUAL HOGARES

\begin{tabular}{ll}
\hline Hogares & Ingreso promedio mensual \\
\hline Total Hogares & $\$ 221.606$ \\
\hline Hogares Jefatura Femenina & $\$ 195.804$ \\
\hline Hogares Jefatura Masculina & $\$ 234.808$ \\
\hline
\end{tabular}

Fuente: Diagnóstico Integral Programa Quiero Mi Barrio- Población Santa Adriana; MINVU; 2007.

juvenil pues hay un número de jóvenes menores de 18 años que actualmente no se encuentran estudiando ni trabajando, proporción que alcanza en total 9\% de los casos. Por otra parte, la condición de vulnerabilidad dada por los bajos niveles de ingreso se agudiza por la precariedad que caracteriza al empleo en materia de protección social ${ }^{43}$. Así lo consigna el mismo diagnóstico de 2007: "un número importante de vecinos acude a la oficina de mediación laboral de la municipalidad, en la cual la mayor parte de los trabajos a los que se accede son de poca calificación, con ingresos muy bajos y sin protección social" ${ }^{\prime 4}$. Ello se corrobora en el relato de una dirigente social entrevistada en 2008:

"Están fuera del sistema de protección social y la gente se siente tremendamente tocada por los salarios... son muy bajos. Hoy día en la comuna hay una OMIL y mandan a trabajar a algunas personas que requieren,

43 Universidad Alberto Hurtado,2007, p. 41

44 Ibídem.

revista invi № 74 / Mayo 2012 / Volumen № 27: 287-313 301 
pero son por salarios horrorosos y la gente decide no ir, prefiere estar cesante y no ir. Entonces otro segmento de la municipalidad dice "es que todos son flojos". Y no son flojos, es que la gente, porque si no se levanta es por algo, es porque tiene una depresión, porque no ve ninguna expectativa y ninguna salida distinta... es una desesperanza" (Mujer Dirigente Social, 53 años).

En términos de educación, la trayectoria de las familias muestra características similares respecto a su precariedad. El análisis histórico de Garcés da cuenta del bajo nivel cultural que tenían los pobladores durante la década del sesenta: "El nivel cultural, anotaban los investigadores de DESAL, es muy bajo a consecuencia de su lamentable situación socioeconómica, y se manifiesta en bajos porcentajes de alfabetismo 'literario y técnico'; bajos niveles de escolaridad y difícil acceso a medios de comunicación" ${ }^{45}$. Asimismo, en el relato de los vecinos se evidencia que los primeros jefes de hogar que se asentaron en la población, tenían un bajo nivel de escolaridad:

"Si yo creo que la media incompleta, los papás nuestros o cabros de mi generación tienen la básica incompleta, séptimo, octavo, séptimo si es que no te embarazaste". (Vecina, Dirigente social, 48 años).

Estos bajos niveles de educación son similares a los que se observan para la última década. Según el estudio de 2007, "sólo el 11,9\% tienen educación básica completa; sólo un 24\% de los jefes de hogar

45 Garcés, Mario. 2002, p. 277. alcanzan niveles de enseñanza media completa, siendo prácticamente insignificantes los niveles de educación superior $(0,8 \%)$. En el caso particular de las mujeres jefas de hogar, esta situación es aún más crítica, lo cual se manifiesta especialmente en que un poco más de la mitad de ellas sólo tiene estudios básicos y que existe un $6,4 \%$ que no tiene ningún tipo de estudios" ${ }^{146}$.

Dada la trayectoria del barrio en materia de ingreso de los hogares, la calidad del empleo y los niveles de educación de las familias, es posible establecer que las condiciones de exclusión económica han sido una constante a lo largo del tiempo.

\section{EL GRADO DE PENETRACIÓN DEL ESTADO EN EL TERRITORIO}

Como se ha señalado antes, una de las variables que incide sobre la integración de las familias al sistema económico es el acceso a servicios y beneficios que entrega el Estado. El análisis de la trayectoria de la oferta pública en la población Santa Adriana evidencia diversas etapas. Cada una de estas etapas está marcada por el énfasis que tuvieron los diferentes programas de gobierno respecto a la superación de la pobreza y de la marginalidad urbana. En base al estudio realizado por Lunecke en 2008, es posible identificar cinco etapas que refieren a la cobertura de la oferta institucional:

46 Universidad Alberto Hurtado, 2007, p. 42. 
a.- 1961- 1965: etapa en la cual Santa Adriana fue foco de la política de vivienda y otros servicios públicos. Por ello, "ya en 1965 los nuevos propietarios de Santa Adriana habían accedido a luz, agua potable, electricidad y habían conseguido que llegara transporte, un consultorio cercano, un retén, una iglesia y que se edificara un colegio en la población"47.

b.- Un segundo período (1965-1973) es aquel en el cual las políticas de promoción popular y fortalecimiento de la participación popular de Frei y Allende, tuvieron un significativo impacto en el acceso a educación, escolarización y mejores empleos vía la sindicalización.

c.- 1973-1990: en este periodo Santa Adriana fue duramente reprimida por la dictadura militar, y abandonada por parte de los programas y beneficios públicos. Ello incidió para que la crisis económica de principios de los ochenta afectara duramente a las familias del barrio.

d.- 1990 -2000: Como consigna el estudio realizado por la Universidad Alberto Hurtado en 2004, "el advenimiento de la democracia es percibido como el "regreso del Estado a la población". Desde entonces los vecinos reconocen el aumento de ayuda social en materia de mayor cobertura de educación, de salud y subsidios para la vivienda, sin embargo aún se reclama la calidad de la oferta pública.

47 PRODEMU, 2004, p. 11. e.- 2000 en adelante: En la última década se identifica una gran inversión de recursos públicos en el territorio. Las intervenciones realizadas por el Ministerio de Interior entre 2002 y 2005 y el aún vigente programa Quiero Mi barrio, de Ministerio de Vivienda y Urbanismo (que se implementa desde 2006), han constituido fuentes de financiamiento permanente orientadas a reducir los factores de riesgo que explican el desarrollo de la delincuencia en el sector y a mejorar las condiciones de vida de los vecinos.

Este análisis permite establecer la relevancia que tiene la presencia del Estado y su oferta institucional en territorios desaventajados. Según el estudio de Lunecke 2008, en los periodos en que la presencia del Estado ha sido más significativa los vecinos destacan un mejor nivel de sus condiciones económicas y sociales. Así lo evidencia el siguiente relato:

\footnotetext{
"Nosotros teníamos un plus de crecimiento en los sesenta, cuando se valoró el derecho de participación del hombre de trabajo, de la clase obrera hacia la universidad. Se dieron más oportunidades de estudiar en la noche para que se hiciera un curso técnico y esas cosas se fueron dando, siento yo que para mi se me cortaron cuando mi padre cayó detenido en el setenta y tres" (Dirigente Social, 53 años).
} 


\section{LA TRAYECTORIA SOCIAL: INTEGRACIÓN SOCIAL, LAZOS SOCIALES Y VÍNCULOS POLÍTICOS}

Como se ha destacado antes, la dimensión social de la exclusión alude a la ruptura de los lazos existentes entre los sujetos y la sociedad producto de la ineficacia para integrarlos por parte de las instituciones de socialización. En barrios de alta vulnerabilidad social y económica, las familias y los establecimientos educacionales son insuficientes para cumplir esta función. Entonces, la organización del barrio y la madurez de sus instituciones vecinales y los tipos de vínculos sociales que se establecen entre los sujetos, pueden jugar un rol fundamental en la socialización y en la superación de los problemas que imponen los procesos de exclusión.

Desde esta aproximación, la trayectoria del vecindario da cuenta de dos tipos de vínculos sociales que han jugado un rol significativo en materia de integración social: los lazos sociales, es decir los lazos de solidaridad, reciprocidad y confianza que existen en un vecindario y los vínculos de carácter político (los que entenderemos como los vínculos de participación vecinal, gremial, sindical y militancia política) de los sujetos.

304 revista invi № 74 / Mayo 2012 / Volumen № 27: 287-313
Respecto a los lazos sociales, quienes llegaron a Santa Adriana eran grupos familiares que venían juntos desde otras poblaciones de la zona sur de Santiago ${ }^{48}$. Estos vínculos permitieron a los primeros pobladores organizarse y obtener mejores condiciones de vida. A partir del Golpe Militar de 1973, la fuerte represión política disminuyó la confianza vecinal y llevó "a que las familias en general se replegaran al espacio privado, aun cuando la cooperación entre los vecinos se mantuvo con el objeto de instalar un sistema de protección a quienes eran perseguidos ${ }^{\prime \prime 4}$. Luego, en el marco de las jornadas de protesta social contra la Dictadura, la represión política mermó muchas de las acciones colectivas que habían comenzado a articularse en clandestinidad e instaló nuevamente la desconfianza interpersonal entre los vecinos.

Lo anterior, junto al patrón cultural individualista, influyó para que desde los noventa, la cooperación y la reciprocidad vecinal se expresaran principalmente en el espacio de la familia y de los amigos más cercanos. Aun cuando muchas organizaciones vecinales se reorganizaron al alero de las políticas sociales impulsadas por los gobiernos de la Concertación, los vínculos sociales de reciprocidad y solidaridad se mantuvieron en el radio más cercano a las familias.

48 Prodemu, 2004, p. 4

49 Prodemu, 2004, p. 17. 
Para la última década, la información disponible confirma esta tendencia. Al respecto, según el censo de 2007 "la mayoría de los vecinos declara relacionarse poco o nada (75\%) con los otros"50. Ello coincide con el hecho de que "quienes establecen relaciones con sus vecinos o buscan apoyo en familias del barrio, lo hacen frecuentemente con personas que viven en su misma calle o pasaje. El apoyo es buscado principalmente en la familia, pues en temas como el cuidado de los hijos se delega dicha tarea fundamentalmente a padres o familiares, dentro del mismo barrio ${ }^{51}$.

En este sentido, la trayectoria de la población en materia de sus lazos comunitarios de un proceso sistemático de reducción de losespacios sociales dondese instala la confianza, la reciprocidad y la solidaridad.

En relación a los vínculos políticos, como mecanismos de integración social, es posible sostener que la historia política de Santa Adriana da cuenta de cómo aquellos vínculos políticos que permitieron en el pasado que sujetos y familias obtuvieran mejores condiciones de vida fueron decayendo a lo largo del tiempo.

Como se ha referido, la fundación de esta población se da en un contexto político en el cual la pobreza y la marginalidad ocupaban un lugar central del debate político. En dichos años, todas las orientaciones favorables al cambio social se expandieron y potenciaron en distintos sectores de la sociedad y tanto la Iglesia como los partidos políticos fueron aliados fundamentales en el desarrollo de estos territorios. Hubo una profunda renovación de las prácticas pastorales y se difundió la teoría de la marginalidad que buscaba integrar socialmente a los más pobres promoviendo sus propias organizaciones. En dicho contexto, Santa Adriana era conocida en la zona sur de Santiago por su capacidad de articulación vecinal y su vinculación a diferentes organizaciones políticas, sociales y autoridades públicas. Garcés destaca el proceso de toma de terreno y la organización de los pobladores como una de las experiencias más exitosas de aquellos años y que fue facilitada por tres factores: el apoyo político que recibieron los pobladores por parte de partidos políticos, especialmente del partido comunista y socialista; el apoyo que recibieron los pobladores por parte de otros dirigentes de poblaciones vecinas y la misma política de promoción popular impulsada en aquellos años, cuyo objetivo era el fortalecimiento de las organizaciones de base y sindicales a lo largo del país.

Después del gobierno de Allende, con la represión política el miedo pasó a ser parte de la cotidianidad del barrio. Muchos vecinos fueron perseguidos y desaparecidos por el terrorismo de Estado. Otros,

50 Universidad Alberto Hurtado, 2007, p. 45.

51 Universidad Alberto Hurtado, 2007, p. 24 
se fueron exiliados fuera del país y sólo a principios de los ochenta se articularon las actividades opositoras al alero de la coordinadora Caro-Ochagavía, que era protegida por la Iglesia. En el marco de las protestas surgieron con fuerza en Santa Adriana, y también ligadas a la labor de la Iglesia, los comités de defensa de los derechos humanos.

Con la llegada de la democracia, volvió también la práctica democrática a las instituciones de la población. Muchas juntas de vecinos se rearticularon. Sin embargo, con el transcurrir del tiempo se debilitó el tejido social organizado. La tríada partidos políticos - la Iglesia Católica - ONG- que había movilizado a los vecinos en el pasado, terminó. Los partidos políticos - producto además de quiebres internos- redujeron su presencia local; la Iglesia se centró en temas específicamente parroquiales dejando de ser referente social, y las ONG vieron mermados sus recursos de origen internacional y redujeron su presencia territorial.

Este quiebre, junto a la despolitización y al desarrollo de una cultura que privilegia más lo privado, explican el debilitamiento organizacional vecinal con que se inició la última década. Durante los últimos diez años, la dirigencia vecinal se reactivó en el marco de los programas focalizados de los programas de gobierno y específicamente en torno a los programas orientados a mejorar la seguridad y los espacios públicos en el barrio. Pese a ello, la representatividad de las organizaciones vecinales es débil si se consideran los bajos niveles de participación social. Así lo consigna la información disponible en 2007: “... del total de hogares censados en 2007 sólo 21\% afirma pertenecer a algún tipo de organización vecinal. Asimismo, los que participan, son en su mayoría adultos mayores, destacándose casi una nula presencia de los más jóvenes. La principal explicación, es el desinterés y la falta de tiempo. Las juntas de vecinos son percibidas por algunos como instancias atomizadas y lejanas a los intereses de la población. La permanencia de los líderes es vista como un problema y también la falta de transparencia y el cuestionamiento a su rol en beneficio de la población". ${ }^{2}$

\section{INTEGRACIÓN CULTURAL DIFERENCIADA: ACTIVIDADES ILEGALES Y EL USO DE LA VIOLENCIA EN SANTA ADRIANA}

Como se ha señalado, la dimensión cultural de la exclusión social refiere a la presencia de mapas valóricos y de normas que organizan la vida comunitaria. En determinados contextos, estas pautas normativas pueden referir a existencia de una cultura alternativa. Este tipo de cultura se presenta cuando las instituciones encargadas de la socialización son insuficientes para integrar a los sujetos en los sistemas de valoraciones y normas sociales vigentes.

52 Universidad Alberto Hurtado, 2007, p. 52. 
En el caso de Santa Adriana y de su historia, es posible evidenciar por un lado, un mosaico de conductas y actividades vinculadas al ilícito, dentro de las cuales el tráfico de drogas es una expresión más. Por otra parte se observa un uso extensivo de la violencia-verbal y física existente en las relaciones entre los vecinos. Estas actividades ilegales y el uso de la violencia como mecanismo de resolución de conflictos constituyen elementos de una cultura valórica y normativa que se aleja de las pautas que rigen al resto de la sociedad.

Respecto al mosaico de ilícitos, el análisis realizado por el estudio etnográfico de la Universidad Alberto Hurtado en 2004 da cuenta de la presencia de actividades ilegales en la historia poblacional. Los mismos vecinos reconocen que desde sus inicios es posible identificar agentes delincuenciales en la población. Así lo destaca un antiguo poblador de 79 años entrevistado:

"Sí, llegaron muchos patos malos acá, pero los que llegamos no éramos na' tan santos tampoco, porque éramos gente de barrio acostumbrada a la dificultad y a defender a los suyos y punto" (Vecino, Hombre, 79 años).

La presencia histórica de figuras delincuenciales coincide con las características delictivas que presenta la población durante la última década. El mismo estudio señala: "la presencia de economías ilegales, que se expresa en actividades como el cogoteo (robo con uso de violencia), lanzazos (hurtos) y robos y en la presencia de figuras como los tíos y las tías (vendedores de droga en el barrio), los domésticos (jóvenes que roban a vecinos para poder consumir drogas), las mecheras (ladronas de ropa) y tendederas (ladronas de ropa en boutiques y malls) configuran el mundo delincuencial existente hasta hoy y que se desarrolla en paralelo a las redes de tráfico de drogas"53.

Dentro de estas figuras las más antiguas son los lanzas y los lanzas internacionales (ladrones que robaban sin uso de fuerza en el extranjero). El estudio etnográfico releva que: "los lanzas en el vecindario forman parte de la historia de la población al ser la categoría delictual más antigua y son en su mayoría hombres adultos. A juicio de los vecinos, este personaje está en declive justamente por la llegada de la droga, la cual es mucho más rentable para los grupos delictivos. A los lanzas, tradicionalmente se los caracterizaba cómo sujetos violentos y temerarios, pero que, bajo ninguna circunstancia serían capaces de robar a vecinos o asaltar dentro de la población" 54 .

Junto a los lanzas, otra figura que se identifica en la trayectoria de la población es la del cogotero (asaltante). Especialmente se les asocia al período de la dictadura militar. Según el mismo estudio, "el asalto y el robo era - a juicio de los vecinos- extendido, y frente a ello las familias debían protegerse

53 Universidad Alberto Hurtado, 2004b, p. 33.

54 Ibídem, p. 35 
y cuidarse" ${ }^{\prime 55}$. Normalmente, estos delitos ocurrían en el trayecto a la casa. Así lo relata una dirigente social de Santa Adriana:

"Sí, si de hecho antes, como los pacos (policía de Carabineros) no se encargaban de ellos, a todos nos iban a dejar a las micros... si tú le preguntas a cualquier vecino de por acá, te va a decir lo mismo... tú tenías que ir a dejar a tu gente a la micro para que no la cogoteen (asalten) y era una cosa real y hoy en día ya no..." (dirigente vecinal, 53 años)

A partir de los noventa, surgen en la población los tíos y las tías (vendedores) vinculados al microtráfico de drogas. Según el reporte: "El menudeo de drogas se realiza en las casas y en algunos negocios del barrio, involucrando al grupo familiar en ello. Se relacionan con las redes de tráfico de drogas para su abastecimiento y reciben dinero por vender" 56 También aparecen las mecheras y tendederas en la población que son en su mayoría, mujeres. Se caracterizan por robar en centros comerciales y supermercados. Su modalidad de trabajo se basa en la familia y especialmente trabajan con sus hijos pequeños o parientes cercanos

Por último, y como se consigna en las entrevistas realizadas en 2008, durante la última década aparecen los domésticos. Son jóvenes que con el fin de consumir drogas, roban en las casas pequeñas mercancías que luego venden, ya sea en la misma población o fuera de ella. Muchos de estos jóvenes son los conocidos como angustiados, que deambulan por la población pidiendo dinero ("cobrando peaje") para poder pagar su alta adicción a la droga, especialmente a la pasta base. Estos jóvenes causan temor y son percibidos como muy agresivos.

Todas estas figuras y actividades configuran un mapa delictual que en muchos casos involucra hechos de violencia y generan temor. Sin embargo, cabe destacar que para muchos vecinos este tipo de actividades se justifica como mecanismo de supervivencia económica.

Por otra parte, se evidencia también el uso de la violencia en las relaciones interpersonales, ya sea en el espacio público como en los hogares. Los antecedentes relevados en la historia oral de la población en 2004 refieren a una larga trayectoria de violencia intrafamiliar, que se confirma con los antecedentes existentes para la última década. El diagnóstico sobre violencia y temor de la Universidad Alberto Hurtado de 2004 consigna que "las agresiones y amenazas en la calle se constituyen como hechos recurrentes. La violencia en los hogares, alude preferentemente a relaciones maritales y/o de filiación, expresándose en altos niveles de violencia intrafamiliar. Este tipo de violencia es identificada en la historia de la población y se asocia a los altos niveles de consumo de alcohol por
55 Ibídem.

56 Ibídem.
ARTíCULO: Violencia urbana, exclusión social y procesos de guetización: La trayectoria de la población Santa Adriana / Graciela Alejandra Lunecke Reyes 
parte de los cónyuges" ${ }^{57}$. Se confirma lo anterior en la experiencia de una antigua vecina cuando narra su propia experiencia:

"y tuve que salir arrancando con mis tres cabros $y$ venirme y tirarme por las murallas para el otro lado de una casa para que me dejaran, porque mi marido me seguia puro pegando y pegando y puro maltratando..." (Vecina, Mujer, 59 años).

Así, "la violencia en el hogar, es posible apreciarlaen sus formas verbales, simbólicas y físicas- a partir de la violencia entre los padres, entre hermanos y la que se recibe directamente. La violencia intrafamiliar es algo que ha estado presente en la población, y que se erige como una de las grandes causantes del deterioro de las familias actuales." 58

Junto a lo anterior, los análisis realizados identifican también el uso de la violencia en las relaciones interpersonales fuera del hogar: "Los vecinos de la Santa Adriana observan que estos fenómenos no son nuevos en su barrio, y que por el contrario, formas de violencia (física y psicológica) son parte de la realidad cotidiana que ha caracterizado a la población durante años. La socialización de la violencia se ha extendido desde el espacio privado al espacio público, instalándose en las escuelas y en espacios comunitarios" 59 . Así lo destaca la siguiente cita de una entrevista:

57 Ibídem, p. 36.

58 Universidad Alberto Hurtado, 2004a , p. 65.

59 Universidad Alberto Hurtado, 2004a , p. 67. “...acá en la Santa Adriana ha sido común desde siempre que la gente resuelve sus problemas a gritos, garabatos, cuchillazos o balazos... Acá predominan los gritos... a gritos, por qué, porque predomina la ley del que grita más entonces, es como quien grita más el que tiene la razón" (Mujer Vecina, 58 años).

De esta forma, la violencia intrafamiliar en la población Santa Adriana y los niveles de agresión en la calle, dan cuenta de la instalación de la violencia como un mecanismo de resolución de conflictos que se ha instalado en las relaciones cotidianas. Existen también lógicas y normas en la población que son permisivas hacia la violencia y la delincuencia. Este mosaico de conductas y actividades configuran un mapa de normas y valores transmitidos y socializados intergeneracionalmente en familias, en escuelas y/o en el barrio, y que si bien no son validadas por todos los vecinos, al menos se naturalizan y justifican como mecanismos de supervivencia.

\section{Conclusiones}

En las páginas anteriores se ha evidenciado que el principal problema que han enfrentado los vecinos de Santa Adriana durante la última década se relaciona con la violencia vinculada al accionar 
de grupos dedicados al tráfico de drogas. Estas bandas han logrado permanecer en el territorio y controlan parte del territorio y lo defienden a través del uso de la violencia armada. Tienen una lógica y estructura organizativa que les permite sustentar el negocio en base a relaciones de alta confianza entre sus miembros y vínculos de amistad con los vecinos. Todo esto ha causado por más de diez años un espiral de violencia que conlleva altos niveles de temor, sentimientos de pérdida del espacio vital y reforzamiento del repliegue de las familias al espacio privado.

En la búsqueda de explicaciones respecto a este fenómeno, el caso de Santa Adriana evidencia la complejidad de este tipo de fenómeno y releva la necesidad de realizar abordajes de carácter multidimensional a partir de perspectivas de largo plazo. Y es que el tráfico de drogas y la violencia asociada a él, requiere que determinadas condiciones sociales, económicas y culturales estén presentes en un territorio determinado.

En este sentido, el tráfico de drogas no sólo necesita una estructura de funcionamiento, de redes de confianza y reciprocidad para hacer funcionar el negocio, sino que necesita especialmente de condiciones de aislamiento social que llevan a una comunidad a justificar su desarrollo.

Santa Adriana muestra cómo los factores de carácter económico se entrelazan con los procesos sociales que vive una comunidad y cómo ambos a su vez dialogan y se fortalecen con aspectos propios de una cultura determinada. Al respecto, la principal lección que arroja este análisis es que los procesos de exclusión social operan en los diferentes ámbitos de la vida de los sujetos, se entrelazan y se refuerzan mutuamente.

Interesa aquí destacar que los procesos de exclusión económica que han afectado a Santa Adriana a lo largo de historia no explican por sí solos el arraigo de las redes de drogas. Si bien las desventajas socioeconómicas son factores determinantes en el desarrollo del mercado de la droga y de otras actividades delictivas, existen variables de carácter cultural y social que inciden en su arraigo. Este es el caso de aquellos mapas normativos que se instalan en determinados grupos sociales y facilitan $(\mathrm{u}$ obstaculizan) el desarrollo de conductas ilícitas y el uso de la violencia.

En el caso de Santa Adriana, la permisividad de los vecinos frente a las actividades ilícitas facilita el desarrollo de este tipo de mercados y refuerza el involucramiento criminal. Asimismo, la instalación de una cultura orientada al desarrollo individual y la privatización de la vida, incide sobre el debilitamiento de los lazos comunitarios que en el pasado permitieron a las familias más pobres superar las condiciones de precariedad material que enfrentaban. Con ello, las probabilidades de superar el aislamiento social han disminuido. 
A la luz de este caso de estudio, es posible sostener que el crimen y la violencia crecen en comunidades empobrecidas, en vía de exclusión y con problemas de convivencia. A su vez el incremento del crimen genera mayores problemas en esos vecindarios. Frente a ello, es responsabilidad de todos impedir el aumento de los territorios de exclusión y de los grupos marginados por la acumulación de exclusiones (de trabajo, de ingresos estables, de reconocimiento social, de escolarización y de hogares integrados, entre otros). Es rol del Estado y de la sociedad toda, fortalecer el derecho a la seguridad entre quienes se encuentran en situación de vulnerabilidad social. También es responsabilidad de todos promover y generar mecanismos que contribuyan a la cohesión social y a la integración de los territorios excluidos.

\section{Bibliografía}

\section{A. FUENTES PRIMARIAS:}

Entrevistas realizadas en el marco de la tesis para optar a Magíster en Desarrollo Urbano de la Pontificia Universidad de Chile en 2008.

Mujer, Vecina, Jefa de Hogar: 58 años Hombre, Vecino, Jefe de Hogar: 55 años. Mujer, Vecina, Jefa de Hogar: 57 años. Hombre, Vecino, Jefe de Hogar: 79 años. Mujer, Dirigente Social, Jefa de Hogar: 53 años.
Hombre, Dirigente Social, Jefe de Hogar, Socialista: 45 años.

Mujer, Dirigente Social, Jefa de Hogar, Socialista: 76 años.

Hombre Vecino, Jefe de Hogar: 49 años.

\section{B. FUENTES SECUNDARIAS}

BARROS, Paula; DE LOS RíOS, Danae, y TORCHE, Florencia. Lecturas sobre la Exclusión Social. [En línea]. Informe $N^{\circ}$ 31. OIT 1996. [Fecha de consulta: 11 marzo, 2008].Disponible en: Http://intranet. oit.org.pe/index.php?option=com_content\&task $=$ view\&id $=431 \&$ Itemid $=1154$

BAUMAN, Zigmunt. Vidas desperdiciadas. La modernidad y sus parias. Madrid, Ed. Paidós. 2004. 171 p. ISBN 9789501254266.

DE RAMÓN, Armando. Santiago de Chile. 1541-1991: historia de una sociedad urbana. Santiago de Chile, Ed. Sudamericana. 2000. 287 p. ISBN 978956-8303-70-9.

ECOSOC. Drogas, Violencia y Delincuencia: los efectos a nivel microsocial. Mimeo. 2003

EISSMANN, Ignacio y LUNECKE, Alejandra. Violencia en Barrios Vulnerables. Una aproximación desde la exclusión social. Persona y Sociedad. 19(1): 73100, Abril 2005. ISNN 0716-730X.

ESTIVILL, Jordi. Panorama de la Lucha contra la exclusión social. Conceptos y estrategias. Ginebra. Oficina Internacional del Trabajo. 2003. ISBN $92-$ 2-313652-0. 
FILGUEIRA, Fernando; KATZMAN, Rubén y RODRÍGUEZ, Federico. Las claves generacionales de la integración y exclusión social: adolescencia y juventud en Uruguay y Chile en los albores del siglo XXI. [En línea]. IPES/ Colección de aportes conceptuales, $N^{\circ}$ 3. 2005. [Fecha de consulta: 23 de octubre 2011]. Disponible en:http://www.ucu.edu.uy/ Portals/0/Publico/Facultades/Ciencias\%20Humanas/IPES/Documentos/EC_Numero\%202.pdf

GARCÉS, Mario. Tomando su sitio. El movimiento de pobladores de Santiago, 1957-1970. Santiago de Chile, Ed. LOM. 450 p., 2002. ISBN 956-282477-2.

HABITERRA. Estudio Diagnóstico en la Región Metropolitana. Barrio Santa Adriana. Mimeo. 2006.

KATZMAN, Rubén. La dimensión espacial en las políticas de superación de la pobreza urbana. [En línea]. IPES/ Colección de aportes conceptuales, $\mathrm{N}^{\mathrm{O}}$ 3. 2005. [Fecha de consulta: 20 de octubre 2011]. Disponible en: http://www.eclac.org/publicaciones/xml/7/12537/lcl1790e.pdf

KATZMAN, Rubén. Seducidos y Abandonados: el aislamiento social de los pobres urbanos. [En línea] Revista de la CEPAL 75. 2001. [Fecha de Consulta: 20 de octubre de 2011]. Disponible en: http:// www.eclac.org/publicaciones/xml/6/19326/Katzman.pdf

LUNECKE, Alejandra. La paradoja de la población Santa Adriana. Tráfico de Drogas en una población emblemática. Tesis para optar al grado de Magíster en Desarrollo Urbano. Pontificia Universidad Católica de Chile, 2008.

312 revista invi № 74 / Mayo 2012 / Volumen № 27: 287-313
LUNECKE, Alejandra y RUIZ, Juan Carlos. Capital social y violencia en barrios urbanos críticos. En: DAMMERT, Lucía y ZÚÑIGA, Liza (Eds.). Seguridad y Violencia. Desafíos para la ciudadanía. Santiago. FLACSO- URBAL. 2007. P.225-253. ISBN 978-956-205-219-1.

LUNECKE, Alejandra y VANDERSCHUEREN, Franz. Prevención de la delincuencia Juvenil. BID, UAH y Ministerio de Interior. Santiago. 2004. 152 p. ISBN.03-9741874.

MARCUSE, Peter. Enclaves yes, ghettos no: segregation and the state. Mimeo. EN: International Seminar on Segregation in the City. Lincoln Institute of Land Policy. July, 26-28, 2001.

MINVU PROGRAMA QUIERO MI BARRIO. Diagnóstico Integral de la Población Santa Adriana Comuna de Lo Espejo. RM. Mimeo, 2007.

PEACH, Ceri. The Ghetto and the Ethnic Enclave. En: VARADY, David (ed.) Desegregating the City: Ghettos, enclaves and inequalities. Albany, State University of New York Press. 2005. p. 31-48. ISBN. 079116459-8.

PONTIFICIA UNIVERSIDAD CATÓLICA DE CHILE. Informe encuesta de percepción de violencia y delincuencia, Población Santa Adriana. Mimeo, 2002.

PRODEMU. Apuntes de reconstrucción histórica. Población Santa Adriana. Mimeo, 2004.

SABATINI, Francisco; CÁCERES, Gonzalo, y CERDA, Jorge. Segregación residencial en las principales ciudades chilenas: Tendencias de las tres últi-

ARTÍCULO: Violencia urbana, exclusión social y procesos de guetización: La trayectoria de la población Santa Adriana / Graciela Alejandra Lunecke Reyes 
mas décadas y posibles cursos de acción”. EURE. 27(82): 21-42, 2001. ISSN 0250-7161.

SUTHERLAND, Edwin y CRESSEY, Donald. Principles of Criminology. 8th edition. Lippincott, 1970. p. 689. ISBN. 0397471874

TIRONI, Manuel. Nueva Pobreza Urbana. Vivienda Social y Capital Social en Santiago de Chile, 1985 - 2001. Ed. Ril Editores. Santiago de Chile. 2003. 151 p. ISBN. 956-284-283-7.

UNIVERSIDAD ALBERTO HURTADO. Diagnóstico integrado de violencia, delincuencia y temor. Población Santa Adriana. Mimeo. 2004A.

UNIVERSIDAD ALBERTO HURTADO. Diagnóstico etnográfico de violencia, delincuencia y temor. Población Santa Adriana. Mimeo. 2004b.
UNIVERSIDAD ALBERTO HURTADO. Diagnóstico de percepción de violencia y delincuencia en niños. Población Santa Adriana. Mimeo. 2004c.

UNIVERSIDAD ALBERTO HURTADO- OSUAH. Estudio de caracterización social, física-territorial de tres barrios. Barrio Santa Adriana. Mimeo. 2007.

WACQUANT, Loic. Condenados de la ciudad. Gueto, periferias y Estado. Buenos Aires, Ed. Siglo XXI. 2007. P. 376. ISBN 978-122098-4.

WAQCUANT, Loic. Parias Urbanos. Marginalidad en la Ciudad a comienzos de siglo. Buenos Aires, Ed. Manantial. P. 204. 2001. ISBN 987-500058-2.

WEATHER, Don y LIND, Bronwyn. Delinquent prone communities. Cambridge University Press.UK. 2001. P. 221. ISBN 9780521790940. 